\title{
JNCI 18-0331R2
}

\section{Article}

\section{The influence of adjuvant systemic regimens on contralateral breast cancer risk and receptor subtype}

Iris $\operatorname{Kramer}^{1,2}$, Michael Schaapveld ${ }^{2}$, Hester S.A. Oldenburg ${ }^{3}$, Gabe S. Sonke ${ }^{4}$, Danielle $\mathrm{McCool}^{2}$, Flora E. van Leeuwen ${ }^{2}$, Koen K. Van de Vijver ${ }^{5}$, Nicola S. Russell ${ }^{6}$, Sabine C. Linn ${ }^{4,7}$, Sabine Siesling ${ }^{8,9}$, C. Willemien Menke- van der Houven van Oordt ${ }^{10}$, Marjanka K. Schmidt ${ }^{1,2}$

1 Division of Molecular Pathology, the Netherlands Cancer Institute, Amsterdam, the Netherlands

2 Division of Psychosocial Research and Epidemiology, the Netherlands Cancer Institute, Amsterdam, the Netherlands

3 Department of Surgical Oncology, the Netherlands Cancer Institute, Amsterdam, the Netherlands

4 Department of Medical Oncology, the Netherlands Cancer Institute, Amsterdam, the Netherlands

${ }^{5}$ Department of Pathology, the Netherlands Cancer Institute, Amsterdam, the Netherlands

6 Department of Radiation Oncology, the Netherlands Cancer Institute, Amsterdam, the Netherlands

${ }^{7}$ Department of Pathology, University Medical Centre Utrecht, Utrecht, the Netherlands

${ }^{8}$ Department of Research, Netherlands Comprehensive Cancer Organisation (IKNL), Utrecht, the Netherlands

(C) The Author(s) 2019. Published by Oxford University Press. All rights reserved. For permissions, please email: journals.permissions@oup.com 
${ }^{9}$ Department of Health Technology and Service Research, Technical Medical Center, University of Twente, Enschede, the Netherlands

10 Department of Medical Oncology, VU University Medical Center, Amsterdam, the Netherlands

\section{Corresponding author:}

Marjanka K. Schmidt, PhD

Division of Molecular Pathology, and Division of Psychosocial Research and Epidemiology

Netherlands Cancer Institute

Plesmanlaan 121, 1066 CX Amsterdam, The Netherlands

T: +31205122767

Email: $\underline{\text { mk.schmidt@nki.nl }}$ 


\section{Abstract}

\section{Background}

An increasing number of breast cancer (BC) survivors are at risk of developing contralateral breast cancer $(\mathrm{CBC})$. We aimed to investigate the influence of various adjuvant systemic regimens on, subtype-specific, risk of $\mathrm{CBC}$.

\section{Methods}

This population-based cohort study included female patients diagnosed with first invasive BC between 2003-2010; follow-up was complete until 2016. Clinico-pathological data were obtained from the Netherlands Cancer Registry, and additional data on receptor status through linkage with PALGA: the Dutch Pathology Registry. Cumulative incidences (death and distant metastases as competing risk) and hazard ratios (HRs) were estimated for all invasive metachronous $\mathrm{CBC}$, and $\mathrm{CBC}$-subtypes.

\section{Results}

Of 83,144 BC patients, 2,816 developed a CBC; the 10-year cumulative incidence was $3.8 \%$ (95\% confidence interval $[\mathrm{CI}]=3.7-4.0 \%)$. Overall, adjuvant chemotherapy: $\mathrm{HR}=0.70$; 95\% $\mathrm{CI}=0.62-0.80$, endocrine therapy: $\mathrm{HR}=0.46 ; 95 \% \mathrm{CI}=0.41-0.52$, and trastuzumab with chemotherapy: $\mathrm{HR}=0.57 ; 95 \% \mathrm{CI}=0.45-0.73$ were strongly associated with a reduced $\mathrm{CBC}$ risk. Specifically, taxane-containing chemotherapy $(\mathrm{HR}=0.48 ; 95 \% \mathrm{CI}=0.36-0.62)$ and aromatase inhibitors $(\mathrm{HR}=0.32 ; 95 \% \mathrm{CI}=0.23-0.44)$ were associated with a large $\mathrm{CBC}$ risk reduction. More detailed analyses showed that endocrine therapy statistically significantly decreased the risk of 
ER-positive $\mathrm{CBC} \quad(\mathrm{HR}=0.41 ; 95 \% \mathrm{CI}=0.36-0.47)$, but not ER-negative $\mathrm{CBC} \quad(\mathrm{HR}=1.32$, 95\% CI=0.90-1.93), compared to no endocrine therapy. Patients receiving chemotherapy for ERnegative first $\mathrm{BC}$ had a higher risk of ER-negative $\mathrm{CBC}$ from 5 years of follow-up (HR=2.84; 95\% CI=1.62-4.99), compared to patients not receiving chemotherapy for ER-negative first BC.

\section{Conclusion}

Endocrine therapy, chemotherapy, as well as trastuzumab with chemotherapy reduces CBC risk. However, each adjuvant therapy regimen had a different impact on the CBC-subtype distribution. Taxane-containing chemotherapy and aromatase inhibitors were associated with the largest $\mathrm{CBC}$ risk reduction. 


\section{Introduction}

Breast cancer (BC) survival has increased considerably, largely as a result of increasing use of (neo)adjuvant therapies[1]. As a consequence, a greater number of women are at risk of developing a second primary tumor in the contralateral breast. Studies have shown that the 10year risk of contralateral breast cancer (CBC) is 4-7\%[2-5].

There is increasing evidence that patients who received adjuvant endocrine therapy or chemotherapy for their first $\mathrm{BC}$ have a lower risk of developing CBC. The Early Breast Cancer Trialists' Collaborative Group (EBCTCG) showed that 5-year tamoxifen use was associated with a 38\% reduction in CBC risk after 10 years of follow-up[6]; and adjuvant chemotherapy with a $20 \%$ decrease[7].

CBC patients may have a worse prognosis compared to patients with unilateral $\mathrm{BC}[2,4$, 8, 9]. An explanation for this worse prognosis, besides having been diagnosed with yet another cancer, may be found in the impact of adjuvant systemic therapy on CBC tumor biology[9], or due to misclassification of metastatic disease as a $\mathrm{CBC}[8]$.

Little is known about the influence of adjuvant systemic therapy on the (hormone) receptor subtype of CBC. Some studies showed a higher proportion of estrogen receptor (ER)negative $\mathrm{CBC}$ among patients who received endocrine therapy for their first $\mathrm{BC}$ compared to those that did not[10-14]. The studies that evaluated the effects of adjuvant therapy on subtypespecific CBC risk, however, were based on small numbers. Since adjuvant trastuzumab was introduced for early-stage BC in 2005, the impact on CBC risk has not yet been described. 
We therefore aimed to investigate the influence of different regimens of adjuvant endocrine therapy, chemotherapy, and trastuzumab on $\mathrm{CBC}$ risk overall and by (hormone) receptor subtype within a large population-based cohort of women diagnosed with invasive BC.

\section{Methods}

\section{Study population}

The cohort included 83,144 female patients diagnosed with invasive BC, who underwent surgery, in 2003-2010 (Figure 1). Patients were selected from the population-based Netherlands Cancer Registry (NCR), which contains data on all newly diagnosed cancer patients nationwide. Follow-up for all patients started 3 months after first BC diagnosis; therefore, patients who had developed distant metastases, CBC, or died within 3 months after diagnosis were excluded.

\section{Patient and tumor characteristics}

The NCR provided clinico-pathological data; follow-up on second cancers and vital status was complete until February $1^{\text {st }} 2016$, but information of recurrences only completely for patients diagnosed in 2003-2006 and for 56\% in 2007-2008. Pathological information on tumor size (T), lymph node status $(\mathrm{N})$, and metastasis $(\mathrm{M})$ collected was coded into tumor stage according to the TNM Classification of Malignant Tumors [15]; if pathological information was missing, clinical stage was used.

The NCR records receptor status determined by immunohistochemistry (IHC) since 2003. Tumors were defined ER-positive or progesterone receptor (PR)-positive when at least $10 \%$ of tumor cells stained positive. In the Netherlands, recommendations for HER2/neu- 
receptor (HER2) testing and use of adjuvant trastuzumab were implemented from 2005[16]. A tumor was considered HER2-positive if IHC 3+ (strong and complete membranous expression in $>10 \%$ of tumor cells) or if IHC $2+$ when additional confirmation with in situ hybridization (ISH) was available, but considered unknown if ISH confirmation was missing. To overcome incompleteness in data on receptor status, all CBC patients were linked to the nationwide network and registry of histo- and cytopathology (PALGA)[17] to retrieve where possible information on ER/PR/HER2 status for both the first $\mathrm{BC}$ and $\mathrm{CBC}$.

Data were handled in accordance to privacy regulations for medical research[18]. The review boards of the NCR and PALGA approved the proposal. All data were anonymous to the researchers involved.

\section{Statistical analysis}

The primary outcome was the development of metachronous $\mathrm{CBC}$, defined as an invasive $\mathrm{BC}$ in the contralateral breast at least 3 months after the first $\mathrm{BC}$ diagnosis. Time at risk ended at the date of $\mathrm{CBC}$, distant metastases, death, or end of follow-up, whichever came first. The cumulative incidence of $\mathrm{CBC}$ was estimated with distant metastases and death as competing risks.

Multivariable Cox Proportional Hazards (CPH) analysis with time since first BC diagnosis as time-scale was used to examine the effect of adjuvant systemic therapy (chemotherapy, endocrine therapy, trastuzumab, or combined) on CBC risk (hazard ratios [HRs]). Subdistribution HRs (SHRs) were calculated accounting for death and distant metastases as competing risks. We examined the association between specific types of chemotherapy (taxane-containing/anthracycline-containing) and endocrine therapy (tamoxifen/aromatase 
inhibitors) and $\mathrm{CBC}$ risk. All models included all systemic therapies and were adjusted for age and stage (III versus I-II) at first BC diagnosis, factors that were previously shown to be important predictors of $\mathrm{CBC}$ in the Dutch population[2], though in our dataset only stage changed the $\log$ HR of systemic therapy with $>15 \%$. Radiotherapy, ER-status, HER2-status, and year of diagnosis did not change the log HR with more than $15 \%$, and were only included for sensitivity analyses. Using the nlcheck function in STATA there was no evidence for nonlinearity of age in the multivariable model[19]; therefore age was continuous in all models, except for Supplementary Tables 1-3 to illustrate the differences between age categories. Since the NCR did not register menopausal status, we used age $<50$ and $\geq 50$ years as a proxy for preand post-menopausal status[20]. Potential effect modification of menopause was assessed with a specification link test for single-equation models[21, 22]. The proportional hazard assumption was assessed using Schoenfeld residuals[23]. We performed sensitivity analyses based on selection of years with complete recurrence information, additional censoring on local/regional recurrence, and a stricter definition of metachronous $\mathrm{CBC}(\geq 1$ year after first $\mathrm{BC})$.

The effect of adjuvant therapy on subtype-specific CBC was estimated using cumulative incidence curves, additionally accounting for other $\mathrm{CBC}$-subtypes as competing risks; e.g. to determine risk of ER-positive $\mathrm{CBC}$, the following events were treated as competing risks: ERnegative CBC, ER-unknown CBC, distant metastases, and death. The HER2-specific analysis only included patients diagnosed since 2005 . Since there was interaction between treatment and subtype ( $\mathrm{P}_{\text {interaction }}<.001$ ), we used joint multivariable $\mathrm{CPH}$ analyses[24] to determine the association of adjuvant therapies with CBC ER-status in separate models for each of the first BC subtypes. We defined subtype as hormone receptor (HR)+/HER2- (i.e. ER+ and/or PR+ \& HER2-), HR+/HER2+ (i.e. ER+ and/or PR+ \& HER2+), HR-/HER2+ (i.e. ER-/PR-/HER2+), 
and HR-/HER2- (i.e. ER-/PR-/HER2-). Each model included ER-specific CBC (ERpositive/ER-negative/ER-unknown), distant metastases, and death as possible outcome. These subtype-specific models were adjusted for trastuzumab, age and stage.

All P-values are two sided; with the statistical significance level set at <.05. Tests for heterogeneity between subtypes or follow-up period were performed using the Wald test. Analyses were performed using STATA, version 13.1 (StataCorp).

\section{Results}

The cohort included for analyses comprised 83,144 patients diagnosed with invasive first BC with a median follow-up of 7.7 years (range 0.3-13.1) (Figure 1). Median time to develop a CBC $(\mathrm{N}=2,816)$ after a first $\mathrm{BC}$ was 4.6 years (range 0.3-12.7). Characteristics of the cohort are

presented in Table 1. The distributions of adjuvant systemic therapies according to patient and tumor characteristics are presented in Supplementary Table 1.

The 5- and 10-year cumulative incidences of CBC were $1.9 \%$ (95\% confidence interval $[\mathrm{CI}]=1.8-2.0 \%)$ and $3.8 \%(95 \% \mathrm{CI}=3.7-4.0 \%)$, respectively (Supplementary Table 2). CBC cumulative incidence increased at a rate of $0.4 \%$ per year.

In a multivariable $\mathrm{CPH}$ model (Table 2), treatment with adjuvant chemotherapy $(\mathrm{HR}=0.70 ; 95 \% \mathrm{CI}=0.62-0.80)$, endocrine therapy $(\mathrm{HR}=0.46 ; 95 \% \mathrm{CI}=0.41-0.52)$, endocrine and chemotherapy $(\mathrm{HR}=0.35 ; 95 \% \mathrm{CI}=0.31-0.39)$, and chemotherapy combined with trastuzumab $(\mathrm{HR}=0.57 ; 95 \% \mathrm{CI}=0.45-0.73)$ were strongly associated with a reduced $\mathrm{CBC}$ risk compared to patients who did not receive systemic therapy. Patients receiving trastuzumab combined with endocrine therapy and chemotherapy were the least prone to develop $\mathrm{CBC} \quad(\mathrm{HR}=0.24$; 
95\% CI=0.17-0.33; $\mathrm{P}<.05$ compared with any other treatment group; Table 2). Adjustment for radiotherapy, year of diagnosis, ER and HER2 status, or taking distant metastases and death as competing risks into account, did not substantially alter these results (Supplementary Table 3), neither did additional censoring on local and regional recurrence, or a stricter definition of CBC (Supplementary Table 4). Radiotherapy was not associated with CBC risk (HR=0.94; 95\% CI=0.86-1.02; Supplementary Table 3). Therapy-specific analysis showed that taxanecontaining chemotherapy was strongly associated with a $\mathrm{CBC}$ risk reduction $(\mathrm{HR}=0.48$; 95\% CI=0.36-0.62; Table 2) compared to patients who did not receive chemotherapy; but not anthracycline-containing chemotherapy $(\mathrm{HR}=0.91 ; 95 \% \mathrm{CI}=0.77-1.06)$. Treatment with aromatase inhibitors $(\mathrm{HR}=0.32 ; 95 \% \mathrm{CI}=0.23-0.44)$ was associated with a stronger $\mathrm{CBC}$ risk reduction compared to tamoxifen $(\mathrm{HR}=0.48 ; 95 \% \mathrm{CI}=0.44-0.53)\left(\mathrm{P}_{\text {heterogeneity }}=.01\right)$. There was no evidence for effect modification between menopausal status and any adjuvant therapy on $\mathrm{CBC}$ risk.

Because the proportional hazard assumption was violated for chemotherapy, endocrine therapy, and trastuzumab, the multivariable $\mathrm{CPH}$ analyses were also performed stratified for follow-up duration $\leq 5$ and $>5$ year (Table 2)[25], following higher recurrence risk reductions for the period $\leq 5$ years shown by the EBCTCG[6, 26]. In our study, CBC risk was statistically significantly stronger reduced in the first 5 years of follow-up among patients who had received chemotherapy and endocrine therapy combined $\left(\mathrm{P}_{\text {heterogeneity }}<.001\right)$, or chemotherapy and trastuzumab combined $\left(\mathrm{P}_{\text {heterogeneity }}=.04\right)$ than in the period $>5$ years follow-up. However, overall, systemic therapy remained statistically significantly associated with a reduced $\mathrm{CBC}$ risk $>5$ years of follow-up.

Patients diagnosed with stage III first BC showed a statistically significantly higher risk of $\mathrm{CBC}(\mathrm{HR}=1.48 ; 95 \% \mathrm{CI}=1.30-1.69)$ compared to patients with stage I-II, but not if distant 
metastases and death were taken into account as competing risks (Supplementary Table 1). CBC risk did not differ by age at first BC, apart from a lower CBC risk for patients aged 45-54 $(\mathrm{HR}=0.88 ; 95 \% \mathrm{CI}=0.80-0.98)$ and $\geq 85$ years $(\mathrm{HR}=0.55 ; 95 \% \mathrm{CI}=0.37-0.81)$ compared to patients aged 55-64 years.

A greater proportion of CBCs among patients treated with endocrine therapy was ERnegative (23.2\%), compared to that among patients without endocrine therapy for ER-positive first BC (6.9\%; Supplementary Table 5). The proportion of ER-negativity between the first BC and $\mathrm{CBC}$ of all patients did not differ (both 18.3\%; Table 1). Among patients with ER-positive first BC (Figure 2A), the difference for ER-positive CBC was 3.4\% after 10-year of follow-up between patients who received endocrine therapy $(1.8 \% ; 95 \% \mathrm{CI}=1.6-2.0)$ and those who did not (5.2\%; 95\%CI=4.9-5.5). Multivariable joint $\mathrm{CPH}$ analyses (Table 3) classifying the first BCs in four BC subtypes, showed that among patients diagnosed with $\mathrm{HR}+/ \mathrm{HER} 2-$ first $\mathrm{BC}$, endocrine therapy statistically significantly decreased the risk of ER-positive CBC (HR=0.41; 95\% CI=0.36-0.47), but not ER-negative CBC $(\mathrm{HR}=1.32 ; 95 \% \mathrm{CI}=0.90-1.93)\left(\mathrm{P}_{\text {heterogeneity }}=<.001\right)$.

We observed a 10-year cumulative incidence of ER-negative CBC of $1.9 \%$ (95\%CI=1.62.2) for patients who received chemotherapy for ER-negative first $\mathrm{BC}$, and $1.2 \%(95 \% \mathrm{CI}=0.9$ 1.6) for patients who did not (Figure 2B). Multivariable joint $\mathrm{CPH}$ analyses showed that patients diagnosed with HR-/HER2- (triple negative) first BC had a higher risk of triple-negative CBC when they received adjuvant chemotherapy $(\mathrm{HR}=1.56 ; 95 \% \mathrm{CI}=1.00-2.42)$, compared to patients who did not (Supplementary Figure 1). In subsequent analyses within ER-negative tumors (insufficient data for triple negatives), we found no association between chemotherapy received for ER-negative first $\mathrm{BC}$ and risk of an ER-negative $\mathrm{CBC}$ in the first 5 years of follow-up $(\mathrm{HR}=1.28 ; 95 \% \mathrm{CI}=0.84-1.95)$. However, risk of ER-negative $\mathrm{CBC}$ was increased for patients 
treated with chemotherapy after $>5$ years follow-up $(\mathrm{HR}=2.84 ; 95 \% \mathrm{CI}=1.62-4.99)$, compared to patients who did not receive chemotherapy for ER-negative first BC. Therapy-specific analyses (Supplementary Table 6) showed a statistically non-significant increased risk of ER-negative $\mathrm{CBC}$ for anthracycline-containing chemotherapy $(\mathrm{HR}=1.32 ; 95 \% \mathrm{CI}=0.86-2.04)$, which was the strongest $>5$ years of follow-up $(\mathrm{HR}=1.88 ; 95 \% \mathrm{CI}=0.91-3.86)$, but a statistically significant decreased risk for taxane-containing chemotherapy $(\mathrm{HR}=0.36 ; 0.17-0.75)$. The combination of taxane- and anthracycline-containing chemotherapy was associated with a statistically nonsignificant decreased risk of ER-negative CBC $(\mathrm{HR}=0.59 ; 95 \% \mathrm{CI}=0.28-1.22$; Supplementary Table 6). The proportion of HER2-positive CBC was $33.7 \%$ for patients treated with trastuzumab for HER2-positive first BC (Supplementary Table 7) with a 5-year cumulative incidence of $0.4 \%(95 \% \mathrm{CI}=0.3-0.7$; Figure $2 \mathrm{C})$, and this was $12.0 \%$ for patients that did not receive trastuzumab, with a 5-year cumulative incidence of $0.2 \%(95 \% \mathrm{CI}=0.1-0.4$; Figure 2C).

\section{Discussion}

In this population-based cohort study comprising $83,144 \mathrm{BC}$ patients, we observed a 10-year cumulative incidence of metachronous $\mathrm{CBC}$ of $3.8 \%$. Overall, receipt of adjuvant chemotherapy, endocrine therapy, and/or trastuzumab with chemotherapy was strongly associated with a reduced $\mathrm{CBC}$ risk. More detailed analyses showed that endocrine therapy was only associated with a reduced risk of ER-positive $\mathrm{CBC}$ and did not protect against the development of ERnegative $\mathrm{CBC}$. Patients receiving chemotherapy for ER-negative first $\mathrm{BC}$ had a higher risk of ER-negative $\mathrm{CBC}>5$ years of follow-up, compared to patients who did not receive chemotherapy for ER-negative first BC. 
The 10-year cumulative incidence of $\mathrm{CBC}$ in our study was relatively low compared to earlier studies[3, 4, 27], but consistent with other, more contemporary studies[2, 5, 28, 29]. In our study, adjuvant endocrine therapy, chemotherapy, and trastuzumab combined with chemotherapy were associated with overall 54\%, 30\%, and 43\% risk reductions of $\mathrm{CBC}$, respectively. The risk reductions associated with endocrine therapy and chemotherapy in our study are slightly higher than the reductions seen in meta-analyses of the EBCTCG[6, 7, 26]. Radiotherapy was not associated with an increased CBC risk, which is consistent with other studies with a mean follow-up time $<15$ years[2, 29-31].

We observed a strongly reduced $\mathrm{CBC}$ risk among patients treated with taxane-containing chemotherapy. The increase in use of taxane-containing chemotherapy coincided with a declining trend in $\mathrm{CBC}$ incidence over the years (Supplementary Table 2). Unfortunately, we have no biological explanation for the different effect of taxanes versus anthracyclines. However, our finding is consistent with a randomized adjuvant trial showing an improvement in diseasefree survival for docetaxel and cyclophosphamide (TC) compared with doxorubicin and cyclophosphamide (AC)[32]. The WECARE case-control study[33] found a lesser, nonsignificant $\mathrm{CBC}$ risk reduction among patients treated with taxane-containing or with anthracycline-containing chemotherapy of $\sim 0.80$, but patients were diagnosed in an earlier period (1986-2008) and the study had smaller numbers.

Little is known about the influence of chemotherapy on subtype distribution of CBC. In our study, adjuvant chemotherapy provided for ER-negative first BC was associated with a decreased risk of ER-positive $\mathrm{CBC}$, which might partly be explained by chemotherapy-induced amenorrhea[34, 35]. However, we found an increased risk of ER-negative CBC for patients receiving chemotherapy $>5$ years of follow-up. This might possibly be a chance finding. Another 
possibility is that the ER-negative $\mathrm{CBCs}$ that developed $>5$ years were chemotherapy-induced tumors. Although effects were not statistically significant because of small numbers, our therapyspecific analyses showed that this increased risk was only seen in the anthracycline-containing chemotherapy group, which is consistent with earlier reports discussing that anthracyclines might increase the risk of development of $\mathrm{BC}[36,37]$. Possibly the risk is only seen for ER-negative CBC because the ER-positive $\mathrm{CBCs}$ were prevented due to endocrine therapy irrespectively. The protective effect of taxane-containing chemotherapy seemed attenuated when given in combination with anthracyclines, which might indicate that the increased effect of anthracyclines may be counteracted by taxanes. Thus, anthracycline-containing chemotherapy might induce ERnegative $\mathrm{CBC}$, but further research will be needed to establish the definite role of anthracyclines in second BC development.

We found a larger reduction in $\mathrm{CBC}$ risk among patients who received aromatase inhibitors compared to tamoxifen. This finding is consistent with a meta-analysis of randomized trials, which observed that the carryover benefit for $\mathrm{CBC}$ was larger for patients randomized to aromatase inhibitors versus tamoxifen[38]. Although endocrine therapy was associated with an overall statistically significantly decreased CBC risk, we and others[33, 39, 40] showed that it was particularly effective in reducing risk of ER-positive $\mathrm{CBC}$, while the risk of ER-negative CBC did not decrease. This is consistent with endocrine therapy selectively inhibiting growth of ER expressing tumor cells, thus reducing the incidence of ER-positive BCs only[6, 41].

It was not possible to investigate the individual effect of trastuzumab on $\mathrm{CBC}$ risk, since all patients received trastuzumab combined with chemotherapy. Besides, we were not able to perform multivariable $\mathrm{CPH}$ analyses to assess the effect of trastuzumab on HER2-specific CBC because of small numbers of $\mathrm{CBCs}$ within this subgroup. Our cumulative incidence curve 
suggests a slightly higher risk of HER2-positive $\mathrm{CBC}$ for patients treated with, compared to patients not treated with trastuzumab. We expected a reduction of HER2-positive CBC after trastuzumab as a consequence of elimination of HER2-overexpressing clones[42].

We observed an increased $\mathrm{CBC}$ risk for patients diagnosed with a stage III first $\mathrm{BC}$ in the cause-specific $\mathrm{CPH}$ model, while there was no association when taking death and distant metastases into account as competing risks. This suggests that part of CBCs were in fact metastases even though these were considered to be by definition a second primary BC. One study, assessing the relationship between first BC and CBC using exome sequencing, has shown that $12 \%$ of $\mathrm{CBC}$ represents metastatic spread from the first $\mathrm{BC}$ [43]. We attempted to minimize the contribution of metastases to the contralateral breast beforehand by starting follow-up 3 months after first $\mathrm{BC}$ diagnosis, only including patients without distant metastasis at initial diagnosis, and censoring for distant metastases during follow-up. Sensitivity analyses showed that additional censoring on local and regional recurrence, or a stricter definition of $\mathrm{CBC}$ did not alter the results (Supplementary Table 4).

In our study patients aged $<35$ years did not have a higher $\mathrm{CBC}$ risk compared to older patients, which is in contrast to findings in a previous cohort study using NCR data, including BC patients diagnosed between 1989-2002[2]. A potential explanation for these discrepant observations might be the increasing use of adjuvant systemic therapy in the last two decades[2, 44]. In our study, $96 \%$ of all patients aged $<35$ years at first BC diagnosis received adjuvant systemic therapy, while this was 59\% in the period 1990-2000[45].

This study harbors some limitations. Since this study was observational, patients who received adjuvant systemic therapy differed with respect to some patient and tumor characteristics to patients who did not receive adjuvant therapy (Supplementary Table 1). In the 
years of diagnosis included, patients with favorable tumor characteristics could avoid systemic therapy following Dutch guidelines[46]. Importantly, in the analyses we adjusted for all these characteristics, but the possibility of some unmeasured residual confounding might still exist. Follow-up on recurrences was not completely recorded by the NCR. This could influence our results, since censoring on distant metastases was not possible for patients outside this period. However, sensitivity analyses showed similar results when including only patients diagnosed between 2003-2006 in the analyses (Supplementary Table 4). We lacked data on contralateral prophylactic mastectomy, which could have resulted in an underestimation of the CBC risk. However, our previous cohort study showed that the uptake of contralateral prophylactic mastectomy among BC patients (aged <50) is only 4\% in the Netherlands[47]. Therefore, it is unlikely that this missing information affected our main conclusions. Finally, we had no data available on BRCA1/2 mutation carriership. However, we do not expect that this significantly affected our results, since the proportion of carriers is limited in the general population[47]. We also lacked data on other germline mutations in genes such as $C H E K 2$ or $P A L B 2$, or on breast cancer associated single nucleotide polymorphisms. However, since there is no indication that these mutation carriers are treated differently with adjuvant systemic therapy compared to noncarriers[48-50], or that there is interaction with adjuvant systemic therapy[49, 51], we do not expect that the absence of these data significantly influenced our results.

The main strengths of this study were the use of a large population-based cohort including all BC patients diagnosed between 2003-2010 in the Netherlands, the comprehensive tumor and therapy information, and active follow-up on $\mathrm{CBC}$ occurrence, allowing reliable estimations of CBC risks. 
In conclusion, our large population-based study showed a 10-year cumulative CBC incidence of $3.8 \%$. Adjuvant systemic therapy strongly reduced CBC risk in a subtype-dependent manner. According to this study, there is no clear indication to change current guidelines on adjuvant systemic therapy. Further research disentangling true primary $\mathrm{CBC}$ from metastases may be useful in further personalization of CBC prevention and treatment choices. 


\section{Funding}

This work was supported by the Alpe d'HuZes/Dutch Cancer Society (KWF Kankerbestrijding) (2013-6253 ALPE).

\section{Notes}

The sponsor had no role in the design of the study; the collection, analysis, and interpretation of the data; the writing of the manuscript; and the decision to submit the manuscript for publication. The authors have no conflicts of interest.

We thank the registration team of the Netherlands Comprehensive Cancer Organization (IKNL) for the collection of data for the Netherlands Cancer Registry (NCR) as well as IKNL staff for scientific advice. We acknowledge the PALGA foundation for providing us the linkage with the NCR data. We want to thank all patients whose data we used for this study, and clinicians who treated these patients. 


\section{References}

1. Netherlands Cancer Registry (NCR). Survival and prevalence of cancer (2016). Available from: http://www.cijfersoverkanker.nl/overleving-prevalentie-51.html.

2. Schaapveld M, Visser O, Louwman WJ, et al. The impact of adjuvant therapy on contralateral breast cancer risk and the prognostic significance of contralateral breast cancer: a population based study in the Netherlands. Breast Cancer Res Treat 2008;110(1):189-97.

3. Gao X, Fisher SG, Emami B. Risk of second primary cancer in the contralateral breast in women treated for early-stage breast cancer: a population-based study. Int J Radiat Oncol Biol Phys 2003;56(4):1038-45.

4. Healey EA, Cook EF, Orav EJ, et al. Contralateral breast cancer: clinical characteristics and impact on prognosis. J Clin Oncol 1993;11(8):1545-52.

5. Aalders KC, van Bommel AC, van Dalen T, et al. Contemporary risks of local and regional recurrence and contralateral breast cancer in patients treated for primary breast cancer. Eur J Cancer 2016;63:118-26.

6. Davies C, Godwin J, Gray R, et al. Relevance of breast cancer hormone receptors and other factors to the efficacy of adjuvant tamoxifen: patient-level meta-analysis of randomised trials. Lancet 2011;378(9793):771-84.

7. Early Breast Cancer Trialists' Collaborative Group. Polychemotherapy for early breast cancer: an overview of the randomised trials. Lancet 1998;352(9132):930-42.

8. Font-Gonzalez A, Liu L, Voogd AC, et al. Inferior survival for young patients with contralateral compared to unilateral breast cancer: a nationwide population-based study in the Netherlands. Breast Cancer Res Treat 2013;139(3):811-9. 
9. Hartman M, Czene K, Reilly M, et al. Incidence and prognosis of synchronous and metachronous bilateral breast cancer. J Clin Oncol 2007;25(27):4210-6.

10. Li CI, Daling JR, Porter PL, et al. Adjuvant hormonal therapy for breast cancer and risk of hormone receptor-specific subtypes of contralateral breast cancer. Cancer Res 2009;69(17):6865-70.

11. Arpino G, Weiss HL, Clark GM, et al. Hormone receptor status of a contralateral breast cancer is independent of the receptor status of the first primary in patients not receiving adjuvant tamoxifen. J Clin Oncol 2005;23(21):4687-94.

12. Swain SM, Wilson JW, Mamounas EP, et al. Estrogen receptor status of primary breast cancer is predictive of estrogen receptor status of contralateral breast cancer. J Natl Cancer Inst 2004;96(7):516-23.

13. Stark A, Lu M, Mackowiak P, et al. Concordance of the Hormone Receptors and Correlation of HER-2/neu Overexpression of the Metachronous Cancers of Contralateral Breasts. The breast journal 2005;11(3):183-187.

14. Kaas R, Peterse JL, Hart AA, et al. The influence of tamoxifen treatment on the oestrogen receptor in metachronous contralateral breast cancer. Br J Cancer 2003;88(5):707-10. 15. Edge SB, Compton CC. The American Joint Committee on Cancer: the 7th edition of the AJCC cancer staging manual and the future of TNM. Annals of surgical oncology 2010;17(6):1471-1474.

16. de Munck L, Schaapveld M, Siesling S, et al. Implementation of trastuzumab in conjunction with adjuvant chemotherapy in the treatment of non-metastatic breast cancer in the Netherlands. Breast Cancer Res Treat 2011;129(1):229-33. 
17. Casparie M, Tiebosch A, Burger G, et al. Pathology databanking and biobanking in The Netherlands, a central role for PALGA, the nationwide histopathology and cytopathology data network and archive. Analytical Cellular Pathology 2007;29(1):19-24.

18. Federa. Human Tissue and Medical Research: Code of conduct for responsible use (2011). In;

https://www.federa.org/sites/default/files/digital_version_first_part_code_of_conduct_in_uk_201 1_12092012.pdf.

19. Jann, B. nlcheck: Stata module to check linearity assumption after model estimation, 2008. Available from http://ideas.repec.org/.

20. Hill K. The demography of menopause. Maturitas 1996;23(2):113-27.

21. Tukey JW. One Degree of Freedom for Non-Additivity. Biometrics 1949;5(3):232-242.

22. Pregibon D. Goodness of Link Tests for Generalized Linear Models. Journal of the Royal Statistical Society. Series C (Applied Statistics) 1980;29(1):15-14.

23. Schoenfeld DA. Sample-size formula for the proportional-hazards regression model. Biometrics 1983;39(2):499-503.

24. Xue X, Kim MY, Gaudet MM, et al. A comparison of the polytomous logistic regression and joint cox proportional hazards models for evaluating multiple disease subtypes in prospective cohort studies. Cancer Epidemiol Biomarkers Prev 2013;22(2):275-85.

25. Kleinbaum DG, Klein M. Survival analysis: Springer; 2010.

26. Early Breast Cancer Trialists' Collaborative Group. Tamoxifen for early breast cancer: an overview of the randomised trials. The Lancet 1998;351(9114):1451-1467.

27. Broet P, de la Rochefordiere A, Scholl SM, et al. Contralateral breast cancer: annual incidence and risk parameters. J Clin Oncol 1995;13(7):1578-83. 
28. Bertelsen L, Bernstein L, Olsen JH, et al. Effect of systemic adjuvant treatment on risk for contralateral breast cancer in the Women's Environment, Cancer and Radiation Epidemiology Study. J Natl Cancer Inst 2008;100(1):32-40.

29. Hooning MJ, Aleman BM, Hauptmann M, et al. Roles of radiotherapy and chemotherapy in the development of contralateral breast cancer. J Clin Oncol 2008;26(34):5561-8.

30. Drooger J, Akdeniz D, Pignol JP, et al. Adjuvant radiotherapy for primary breast cancer in BRCA1 and BRCA2 mutation carriers and risk of contralateral breast cancer with special attention to patients irradiated at younger age. Breast Cancer Res Treat 2015;154(1):171-80.

31. Pierce LJ, Phillips KA, Griffith KA, et al. Local therapy in BRCA1 and BRCA2 mutation carriers with operable breast cancer: comparison of breast conservation and mastectomy. Breast Cancer Res Treat 2010;121(2):389-98.

32. Jones SE, Savin MA, Holmes FA, et al. Phase III trial comparing doxorubicin plus cyclophosphamide with docetaxel plus cyclophosphamide as adjuvant therapy for operable breast cancer. J Clin Oncol 2006;24(34):5381-7.

33. Langballe R, Mellemkjaer L, Malone KE, et al. Systemic therapy for breast cancer and risk of subsequent contralateral breast cancer in the WECARE Study. Breast Cancer Res 2016;18(1):65.

34. Valentini A, Finch A, Lubinski J, et al. Chemotherapy-induced amenorrhea in patients with breast cancer with a BRCA1 or BRCA2 mutation. J Clin Oncol 2013;31(31):3914-9.

35. Zavos A, Valachis A. Risk of chemotherapy-induced amenorrhea in patients with breast cancer: a systematic review and meta-analysis. Acta Oncol 2016;55(6):664-70. 
36. Henderson TO, Moskowitz CS, Chou JF, et al. Breast Cancer Risk in Childhood Cancer Survivors Without a History of Chest Radiotherapy: A Report From the Childhood Cancer Survivor Study. J Clin Oncol 2016;34(9):910-8.

37. Leeuwen FEv, Ronckers CM. Anthracyclines and Alkylating Agents: New Risk Factors for Breast Cancer in Childhood Cancer Survivors? Journal of Clinical Oncology 2016;34(9):891894.

38. Aromatase inhibitors versus tamoxifen in early breast cancer: patient-level meta-analysis of the randomised trials. Lancet 2015;386(10001):1341-1352.

39. Bouchardy C, Benhamou S, Fioretta G, et al. Risk of second breast cancer according to estrogen receptor status and family history. Breast Cancer Res Treat 2011;127(1):233-41.

40. Gierach GL, Curtis RE, Pfeiffer RM, et al. Association of adjuvant tamoxifen and aromatase inhibitor therapy with contralateral breast cancer risk among us women with breast cancer in a general community setting. JAMA Oncology 2017;3(2):186-193.

41. Manna S, Holz MK. Tamoxifen Action in ER-Negative Breast Cancer. Sign Transduct Insights 2016;5:1-7.

42. Guarneri V, Dieci MV, Barbieri E, et al. Loss of HER2 positivity and prognosis after neoadjuvant therapy in HER2-positive breast cancer patients. Ann Oncol 2013;24(12):2990-4. 43. Klevebring D, Lindberg J, Rockberg J, et al. Exome sequencing of contralateral breast cancer identifies metastatic disease. Breast Cancer Res Treat 2015;151(2):319-24.

44. Kollias J, Ellis IO, Elston CW, et al. Prognostic significance of synchronous and metachronous bilateral breast cancer. World J Surg 2001;25(9):1117-24. 
45. Engelhardt EG, van den Broek AJ, Linn SC, et al. Accuracy of the online prognostication tools PREDICT and Adjuvant! for early-stage breast cancer patients younger than 50 years. Eur J Cancer 2017;78:37-44.

46. Oncoline, cancer clinical practice guidelines, versie 1.0. Endocriene therapie. Available from: https://www.oncoline.nl/borstkanker.

47. van den Broek AJ, van 't Veer LJ, Hooning MJ, et al. Impact of Age at Primary Breast Cancer on Contralateral Breast Cancer Risk in BRCA1/2 Mutation Carriers. J Clin Oncol 2016;34(5):409-18.

48. Schmidt MK, Tollenaar RA, de Kemp SR, et al. Breast cancer survival and tumor characteristics in premenopausal women carrying the CHEK2*1100delC germline mutation. $\mathrm{J}$ Clin Oncol 2007;25(1):64-9.

49. Kriege M, Hollestelle A, Jager A, et al. Survival and contralateral breast cancer in CHEK2 1100delC breast cancer patients: impact of adjuvant chemotherapy. Br J Cancer 2014;111(5):1004-13.

50. Cybulski C, Kluzniak W, Huzarski T, et al. Clinical outcomes in women with breast cancer and a PALB2 mutation: a prospective cohort analysis. Lancet Oncol 2015;16(6):638-44. 51. Teraoka SN, Bernstein JL, Reiner AS, et al. Single nucleotide polymorphisms associated with risk for contralateral breast cancer in the Women's Environment, Cancer, and Radiation Epidemiology (WECARE) Study. Breast Cancer Res 2011;13(6):R114. 
Table 1. Patient, tumor, and treatment characteristics of all patients diagnosed with first breast cancer between 2003-2010 and subsequent contralateral breast cancer

\begin{tabular}{|c|c|c|}
\hline Characteristics & $\begin{array}{c}\text { First breast cancer } \\
\text { No. }(\%)^{*}\end{array}$ & $\begin{array}{c}\text { Contralateral breast cancer } \\
\text { No. }(\%)^{*}\end{array}$ \\
\hline Total & $83,144(100.0)$ & $2,816(100.0)$ \\
\hline \multicolumn{3}{|l|}{ Age at diagnosis, $y$} \\
\hline$<35$ & $1,826(2.2)$ & $22(0.8)$ \\
\hline $35-44$ & $9,693(11.7)$ & $153(5.4)$ \\
\hline $45-54$ & $22,154(26.7)$ & $523(18.6)$ \\
\hline $55-64$ & $21,778(26.2)$ & $801(28.4)$ \\
\hline $65-74$ & $17,222(20.7)$ & $771(27.4)$ \\
\hline $75-84$ & $8,242(9.9)$ & $444(15.8)$ \\
\hline$\geq 85$ & $2,229(2.7)$ & $102(3.6)$ \\
\hline Median age at diagnosis, $\mathrm{y}$ (range) & $58.5(19.4-101.3)$ & $63.9(24.8-97.0)$ \\
\hline \multicolumn{3}{|l|}{ Tumor stage } \\
\hline $\mathrm{I}$ & $39,676(47.7)$ & $1,736(63.3)$ \\
\hline II & $32,158(38.7)$ & $703(25.6)$ \\
\hline III & $11,310(13.6)$ & $237(8.6)$ \\
\hline IV & $\dagger$ & $68(2.5)$ \\
\hline Unknown & $\dagger$ & 72 \\
\hline \multicolumn{3}{|l|}{ Histological grade } \\
\hline Grade 1 & $17,393(22.8)$ & $706(28.9)$ \\
\hline Grade 2 & $34,153(44.8)$ & $1,091(44.6)$ \\
\hline Grade $3 \div$ & $24,632(32.3)$ & $647(26.5)$ \\
\hline Unknown & 6,966 & 372 \\
\hline \multicolumn{3}{|l|}{ Morphology } \\
\hline Ductal & $64,044(77.0)$ & $2,051(72.8)$ \\
\hline Lobular & $9,233(11.1)$ & $380(13.5)$ \\
\hline Mixed ductal/lobular & $3,013(3.6)$ & $112(4.0)$ \\
\hline Other & $6,854(8.2)$ & $273(9.7)$ \\
\hline \multicolumn{3}{|l|}{ ER status } \\
\hline Positive & $64,886(81.7)$ & $2,200(81.7)$ \\
\hline Negative & $14,579(18.3)$ & $492(18.3)$ \\
\hline Unknown & 3,679 & 124 \\
\hline \multicolumn{3}{|l|}{ PR status } \\
\hline Positive & $50,674(66.1)$ & $1,618(61.6)$ \\
\hline Negative & $26,004(33.9)$ & $1,010(38.4)$ \\
\hline Unknown & 6,466 & 188 \\
\hline \multicolumn{3}{|l|}{ HER2 status } \\
\hline Positive & $11,061(17.3)$ & $335(12.6)$ \\
\hline Negative & $52,956(82.7)$ & $2,314(87.4)$ \\
\hline Unknown & 19,127 & 167 \\
\hline \multicolumn{3}{|l|}{ Subtype $\|$} \\
\hline HR+/HER2- & $45,441(71.8)$ & $1,935(74.9)$ \\
\hline HR+/HER2+ & $6,957(11.0)$ & $189(7.3)$ \\
\hline HR-/HER2+ & $3,618(5.7)$ & $117(4.5)$ \\
\hline HR-/HER2- & $7,304(11.5)$ & $344(13.3)$ \\
\hline Unknown & 19,824 & 231 \\
\hline \multicolumn{3}{|l|}{$\begin{array}{l}\text { (Neo)adjuvant therapy for first breast } \\
\text { cancer }\end{array}$} \\
\hline No (neo)adjuvant therapyII & $31,290(37.6)$ & - \\
\hline CT & $8,889(10.7)$ & - \\
\hline ET & $17,359(20.9)$ & - \\
\hline $\mathrm{CT}+\mathrm{ET}$ & $19,923(24.0)$ & - \\
\hline $\mathrm{CT}+\mathrm{TRA}$ & $2,728(3.3)$ & - \\
\hline
\end{tabular}


$\mathrm{CT}+\mathrm{ET}+\mathrm{TRA}$

(Neo)adjuvant CT

\section{No CT}

Taxane-containing CT\#

Anthracycline-containing $\mathrm{CT}^{* *}$

Taxane- + anthracycline-containing CT

$\mathrm{CT}$, other or type unknown $\dagger \dagger$

(Neo)adjuvant ET

No ET

Tamoxifenț

Aromatase inhibitors

Tamoxifenț+ aromatase inhibitors

$$
2,955(3.6)
$$

48,717 (58.6)

$4,427(5.3)$

$6,802(8.2)$

$3,590(4.3)$

$19.608(23.6)$

$42,861(51.6)$

$33,862(40.7)$

$2,393(2.9)$

$4,028(4.8)$

* Percentages may not total 100 because of rounding. ER = estrogen receptor; PR = progesterone receptor; HER2 = human epidermal growth factor receptor2; $\mathrm{HR}+=$ hormone receptor positive; $\mathrm{HR}-=$ hormone receptor negative; $\mathrm{CT}$ $=$ chemotherapy; $\mathrm{ET}=$ endocrine therapy; $\mathrm{TRA}=$ trastuzumab; No. $=$ number

$\dagger$ Excluded

* Including 12 first breast cancers and 1 contralateral breast cancer that were defined as 'undifferentiated' in the Netherlands Cancer Registry

$\S$ HER2 status distribution of first breast cancer from 2005-2010: positive $\mathrm{N}=10.388$ (17.0\%), negative $\mathrm{N}=50.652$ (83.0\%), unknown $\mathrm{N}=2.313$

$\| \mathrm{HR}+=\mathrm{ER}+$ and $/$ or $\mathrm{PR}+; \mathrm{HR}-=\mathrm{ER}-$ and $\mathrm{PR}-$

II No chemotherapy, endocrine therapy or trastuzumab (with or without radiotherapy)

\# The chemotherapeutic combination contains taxanes, but no anthracyclines

** The chemotherapeutic combination contains anthracyclines, but no taxanes

$\dagger \dagger$ All other chemotherapeutic drugs and combinations (e.g. CMF) or type unknown

$\$$ The Netherlands Cancer Registry specifically codes aromatase inhibitors; Tamoxifen is coded as endocrine therapy 
Table 2. Multivariable Cox regression analyses of contralateral breast cancer risk related to the (neo)adjuvant systemic therapy for the first breast cancer

\begin{tabular}{|c|c|c|c|c|c|c|c|c|c|c|c|c|c|c|c|}
\hline \multirow[b]{2}{*}{ (Neo)adjuvant systemic therapy } & \multicolumn{4}{|c|}{ Total follow-up } & \multicolumn{5}{|c|}{$\leq 5$ years follow-up } & \multicolumn{5}{|c|}{$>5$ years follow-up } & \multirow{2}{*}{ 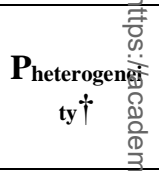 } \\
\hline & $\begin{array}{c}\text { No. of } \\
\text { patient } \\
\text { s } \\
\end{array}$ & HR & $95 \% \mathrm{CI}$ & $\mathbf{P}^{*}$ & $\begin{array}{c}\text { No. of } \\
\text { patient } \\
\text { s } \\
\end{array}$ & $\begin{array}{l}\text { No. of } \\
\text { CBC }\end{array}$ & HR & $95 \% \mathrm{CI}$ & $\mathbf{P} *$ & $\begin{array}{c}\text { No. of } \\
\text { patient } \\
\text { s } \\
\end{array}$ & $\begin{array}{l}\text { No. of } \\
\text { CBC }\end{array}$ & HR & $95 \% \mathrm{CI}$ & $\mathbf{P} *$ & \\
\hline \multicolumn{16}{|l|}{$\begin{array}{l}\text { Model 1: (Neo)adjuvant therapy } \\
\text { combined } \$\end{array}$} \\
\hline No (neo)adjuvant therapy§ & 31,290 & 1.00 & Ref. & & 4,644 & 913 & 1.00 & Ref. & & 26,646 & 700 & 1.00 & Ref. & & \\
\hline $\mathrm{CT}$ & 8,889 & 0.70 & $0.62-0.80$ & $<.001$ & 2,208 & 172 & 0.66 & $0.56-0.78$ & $<.001$ & 6,681 & 146 & 0.79 & $0.65-0.95$ & .01 & $1 . \underline{\underline{B}}$ \\
\hline ET & 17,359 & 0.46 & $0.41-0.52$ & $<.001$ & 3,678 & 218 & 0.42 & $0.36-0.49$ & $<.001$ & 13,681 & 149 & 0.50 & $0.42-0.60$ & $<.001$ & .19 \\
\hline $\mathrm{CT}+\mathrm{ET}$ & 19,923 & 0.35 & $0.31-0.39$ & $<.001$ & 2,287 & 177 & 0.26 & $0.22-0.30$ & $<.001$ & 17,636 & 227 & 0.50 & $0.42-0.59$ & $<.001$ & $<.00$ 变 \\
\hline $\mathrm{CT}+\mathrm{TRA}$ & 2,728 & 0.57 & $0.45-0.73$ & $<.001$ & 477 & 43 & 0.47 & $0.35-0.64$ & $<.001$ & 2,251 & 33 & 0.77 & $0.54-1.10$ & .16 & .0 争 \\
\hline $\mathrm{CT}+\mathrm{ET}+\mathrm{TRA}$ & 2,955 & $0.24 \|$ & $0.17-0.33$ & $<.001$ & 261 & 21 & 0.20 & $0.13-0.31$ & $<.001$ & 2,694 & 17 & 0.31 & $0.19-0.51$ & $<.001$ & .18 \\
\hline \multicolumn{16}{|l|}{$\begin{array}{l}\text { Model 2: Therapy-specific subgroups } \mathbb{} \\
\text { (Neo)adjuvant CT }\end{array}$} \\
\hline No CT & 48,717 & 1.00 & Ref. & & 8,341 & 1,132 & 1.00 & Ref. & & 40,376 & 849 & 1.00 & Ref. & & \\
\hline Taxane-containing CT\# & 4,427 & 0.48 & $0.36-0.62$ & $<.001$ & 620 & 36 & 0.42 & $0.30-0.58$ & $<.001$ & 3,807 & 24 & 0.64 & $0.42-0.97$ & .04 & $.1 \%$ \\
\hline Anthracycline-containing $\mathrm{CT}^{* *}$ & 6,802 & 0.91 & $0.77-1.06$ & .23 & 1,127 & 100 & 0.85 & $0.68-1.07$ & .16 & 5,675 & 140 & 0.98 & $0.79-1.22$ & .86 & .38 \\
\hline Taxane+anthracycline-containing & 3,590 & & & & 475 & 44 & & & & 3,115 & 27 & & & & $.8 \underline{\underline{3}}$ \\
\hline $\mathrm{CT}$ & & 0.69 & $0.52-0.91$ & .009 & & & 0.71 & $0.50-0.99$ & .05 & & & 0.66 & $0.42-1.06$ & .08 & \\
\hline $\begin{array}{l}\text { CT, other or type unknown } \uparrow \dagger \\
\text { (Neo)adjuvant ET }\end{array}$ & 19,608 & 0.70 & $0.62-0.78$ & $<.001$ & 2,992 & 232 & 0.61 & $0.52-0.71$ & $<.001$ & 16,616 & 232 & 0.84 & $0.71-1.00$ & .05 & $.0 \underset{\omega}{\mathbb{\omega}}$ \\
\hline No ET & 42,861 & 1.00 & Ref. & & 7,319 & 1,127 & 1.00 & Ref. & & 35,542 & 879 & 1.00 & Ref. & & \\
\hline Tamoxifen $+\uparrow$ & 33,862 & 0.48 & $0.44-0.53$ & $<.001$ & 5,458 & 352 & 0.41 & $0.37-0.47$ & $<.001$ & 28,404 & 312 & 0.57 & $0.49-0.65$ & $<.001$ & $.00 \$$ \\
\hline Aromatase inhibitors & 2,393 & 0.32 & $0.23-0.44$ & $<.001$ & 407 & 20 & 0.31 & $0.20-0.48$ & $<.001$ & 1,986 & 18 & 0.33 & $0.20-0.53$ & $<.001$ & $.8 \overrightarrow{8}$ \\
\hline Tamoxifent+ + aromatase inhibitors & 4,028 & 0.45 & $0.36-0.56$ & $<.001$ & 371 & 45 & 0.40 & $0.29-0.55$ & $<.001$ & 3,657 & 63 & 0.50 & $0.38-0.67$ & $<.001$ & .28 \\
\hline $\begin{array}{l}* \text { Two-sided Wald test P-val } \\
=\text { reference group } \\
\dagger \text { Heterogeneity of HRs bety } \\
\text { † Adjusted for age and stage } \\
\S \text { No chemotherapy, endocri } \\
\| \text { We compared the CT+ET+ } \\
\text { CT+TRA, P<.001) } \\
\text { II Adjusted for trastuzumab } t \\
\text { \# The chemotherapeutic com } \\
* * \text { The chemotherapeutic col } \\
\dagger \dagger \text { All other chemotherapeut }\end{array}$ & $\begin{array}{l}\text { een } \leq 5 \text { and } \\
\text { t first bre } \\
\text { e therapy } \\
\text { TRA group } \\
\text { erapy, age } \\
\text { ination co } \\
\text { bination c } \\
\text { drugs an }\end{array}$ & $\begin{array}{l}\text { lemothe } \\
>5 \text { yea } \\
\text { ast canc } \\
\text { or trastu } \\
\text { versus } \\
\text { and sta } \\
\text { ntains t } \\
\text { ontains } \\
\text { d combi }\end{array}$ & $\begin{array}{l}\text { apy; ET end } \\
\text { follow-up } \\
\text { diagnosis } \\
\text { umab (with } \\
\text { he other tre } \\
\text { e at first br } \\
\text { xanes, but n } \\
\text { nthracyclin } \\
\text { ations (e.g. }\end{array}$ & $\begin{array}{l}\text { uration } \\
\text { or witho } \\
\text { tment gi } \\
\text { ast canc } \\
\text { anthrac } \\
\text { s, but no } \\
\text { CMF) or }\end{array}$ & $\begin{array}{l}\text { It radiothe } \\
\text { oups by c } \\
\text { yclines } \\
\text { taxanes } \\
\text { type unkn }\end{array}$ & $\begin{array}{l}\text { rapy) } \\
\text { anging } \\
\text { own }\end{array}$ & refe & $\begin{array}{l}\text { No. }=\text { num } \\
\text { nce (vs. C }\end{array}$ & P<.00 & (vs. ET & $\begin{array}{l}\text {, } \mathrm{CI}= \\
.001)\end{array}$ & $\begin{array}{l}\text { confid } \\
\text { vs. CT }\end{array}$ & $\begin{array}{l}\text { ce interval } \\
\mathrm{ET}, \mathrm{P}=.03)\end{array}$ & $\begin{array}{l}\text { Ref. } \\
\text { vs. }\end{array}$ & 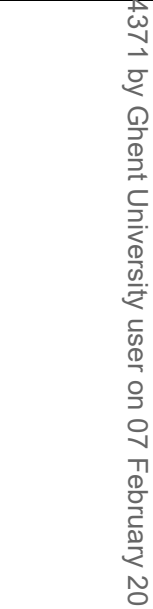 \\
\hline
\end{tabular}


$+t$ The registry specifically codes aromatase inhibitors; Tamoxifen is coded as hormonal treatment 
Table 3. Joint multivariable Cox regression analyses for each of the first tumor subtypes assessing the association of (neo)adjuvant systemic treatment of the first breast cancer with subtype-specific contralateral breast cancer risk*

\begin{tabular}{|c|c|c|c|c|c|c|c|c|c|c|}
\hline \multirow[b]{2}{*}{$\begin{array}{l}\text { Subtype first breast } \\
\text { cancer }\end{array}$} & \multirow[b]{2}{*}{$\begin{array}{c}\text { No. of } \\
\text { patients }\end{array}$} & \multicolumn{4}{|c|}{ ER-positive CBC } & \multicolumn{4}{|c|}{ ER-negative CBC } & \multirow[b]{2}{*}{$\mathbf{P}_{\text {heterogeneity }}$} \\
\hline & & $\begin{array}{l}\text { No. of } \\
\text { CBC } \\
\text { cases }\end{array}$ & HR & $95 \% \mathrm{CI}$ & $\mathbf{P} \dagger$ & $\begin{array}{l}\text { No. of } \\
\text { CBC } \\
\text { cases }\end{array}$ & HR & $95 \% \mathrm{CI}$ & $P \uparrow$ & \\
\hline \multicolumn{11}{|l|}{ Model 1: HR+/HER2-§ } \\
\hline \multicolumn{11}{|l|}{ Endocrine therapy } \\
\hline No endocrine therapy & 18,125 & 860 & 1.00 & Ref. & & 54 & 1.00 & Ref. & & \\
\hline Endocrine therapy & 27,316 & 397 & 0.41 & $0.36-0.47$ & $<.001$ & 107 & 1.32 & $0.90-1.93$ & .15 & $<.001$ \\
\hline \multicolumn{11}{|l|}{ Chemotherapy } \\
\hline No chemotherapy & 28,973 & 1,048 & 1.00 & Ref. & & 100 & 1.00 & Ref. & & \\
\hline Chemotherapy & 16,468 & 209 & 0.56 & $0.46-0.67$ & $<.001$ & 61 & 1.15 & $0.78-1.70$ & .48 & $<.001$ \\
\hline \multicolumn{11}{|l|}{ Model 2: HR+/HER2+§ } \\
\hline \multicolumn{11}{|l|}{ Endocrine therapy } \\
\hline No endocrine therapy & 2,282 & 83 & 1.00 & Ref. & & 8 & 1.00 & Ref. & & \\
\hline Endocrine therapy & 4,675 & 46 & 0.43 & $0.28-0.66$ & $<.001$ & 22 & 1.22 & $0.50-2.98$ & .66 & .04 \\
\hline \multicolumn{11}{|l|}{ Chemotherapy } \\
\hline No chemotherapy & 3,186 & 96 & 1.00 & Ref. & & 13 & 1.00 & Ref. & & \\
\hline Chemotherapy & 3,771 & 33 & 0.61 & $0.29-1.27$ & .19 & 17 & 2.33 & $0.71-6.62$ & .16 & .05 \\
\hline \multicolumn{11}{|l|}{ Model 3: HR-/HER2+§ } \\
\hline \multicolumn{11}{|l|}{ Endocrine therapy } \\
\hline No endocrine therapy & 3,538 & 77 & 1.00 & Ref. & & 36 & 1.00 & Ref. & & \\
\hline Endocrine therapy & 80 & 0 & $7.15 \cdot 10^{-10}$ & $\begin{array}{c}1.67 \cdot 10^{-10}- \\
3.06 \cdot 10^{-9}\end{array}$ & $<.001$ & 2 & 2.19 & $0.51-9.36$ & .29 & - \\
\hline \multicolumn{11}{|l|}{ Chemotherapy } \\
\hline No chemotherapy & 1,041 & 19 & 1.00 & Ref. & & 9 & 1.00 & Ref. & & \\
\hline Chemotherapy & 2,557 & 58 & 1.22 & $0.57-2.64$ & .61 & 29 & 4.01 & $1.64-9.81$ & .002 & .05 \\
\hline \multicolumn{11}{|l|}{ Model 4: HR-/HER2-§ } \\
\hline \multicolumn{11}{|l|}{ Endocrine therapy } \\
\hline No endocrine therapy & 7,126 & 124 & 1.00 & Ref. & & 134 & 1.00 & Ref. & & \\
\hline Endocrine therapy & 178 & 4 & 1.22 & $0.45-3.32$ & .69 & 1 & 0.30 & $0.04-2.13$ & .23 & .21 \\
\hline \multicolumn{11}{|l|}{ Chemotherapy } \\
\hline No chemotherapy & 2,255 & 42 & 1.00 & Ref. & & 32 & 1.00 & Ref. & & \\
\hline Chemotherapy & 5,049 & 86 & 0.60 & $0.38-0.93$ & .02 & 103 & 1.17 & $0.77-1.78$ & .47 & .02 \\
\hline
\end{tabular}


* Adjusted for trastuzumab therapy, age and stage at first breast cancer diagnosis. $\mathrm{CBC}=$ contralateral breast cancer; $\mathrm{HR}+=$ hormone receptor positive; $\mathrm{HR}-=$ hormone receptor negative; $\mathrm{ER}=$ estrogen receptor; HER2 = human epidermal growth factor receptor 2; No = number; $\mathrm{HR}=$ hazard ratio; $\mathrm{CI}=$ confidence interval; Ref. = reference group

$\uparrow$ Two-sided Wald test P-value

$\$$ Heterogeneity of HRs between ER-positive and ER-negative CBC

$\S \mathrm{R}+=\mathrm{ER}+$ and/or $\mathrm{PR}+; \mathrm{HR}^{-}=\mathrm{ER}-$ and $\mathrm{PR}-$ 


\section{Figure legends}

\section{Figure 1. Overview of the selection of breast cancer patients}

*After notification by the nationwide network and registry of histo- and cytopathology in the Netherlands (PALGA) and the national hospital discharge database, trained NCR personnel collected data directly from patients' files.

\section{Figure 2. Cumulative incidence of CBC by ER and HER2 status}

(A) Cumulative incidence curves showing the risk of ER-positive or ER-negative CBC after ERpositive first breast cancer, stratified for adjuvant endocrine therapy. (B) Cumulative incidence curves showing the risk of ER-positive or ER-negative CBC after ER-negative first breast cancer, stratified for adjuvant chemotherapy. (C) Cumulative incidence curves showing the risk of HER2-positive or HER2-negative CBC after HER2-positive first breast cancer, stratified for adjuvant trastuzumab therapy. For these analyses, patients diagnosed with invasive breast cancer between 2003-2004 were excluded because trastuzumab was not yet widely prescribed in those years. Each panel in the figure consist of two cumulative incidence curves combined (duplicated risk table). In all panels, analyses were performed accounting for death, distant metastases, and CBC-subtype as competing risks (e.g. for the analysis of ER-positive CBC, the following events were treated as competing risks: ER-negative $\mathrm{CBC}$, ER-unknown $\mathrm{CBC}$, distant metastases, and death). Abbreviations: $\mathrm{BC}=$ breast cancer; $\mathrm{CBC}=$ contralateral breast cancer; $\mathrm{CT}=$ chemotherapy; ET = endocrine therapy; TRA = trastuzumab; ER = estrogen receptor; HER2 = human epidermal growth factor receptor 2 ; No. = number of patients 
The Netherlands Cancer Registry that includes all primary tumors diagnosed since 1989*

Inclusion criteria:

- Females aged $\geq 18$ years

- Invasive breast cancer

- $\quad$ Diagnosed between January $1^{\text {st }} 2003$ and December $31^{\text {st }} 2010$

- Surgically treated in Dutch hospital

- No prior invasive cancer (other than non-melanoma skin cancer or nonbreast in situ tumors)

$$
N=85,948
$$

Patients diagnosed with invasive contralateral breast cancer

$N=2,816$
Patients excluded $\mathbf{N}=\mathbf{2 , 8 0 4}$

$\mathbf{N}=\mathbf{3}$ First breast cancer diagnosis without cytological or histological confirmation

$\mathbf{N}=1,346$ Diagnosed with stage IV or unknown

$\mathbf{N}=19$ Squamous cell carcinoma $\mathbf{N}=\mathbf{1 , 4 3 6}$ Patients died, developed distant metastases or (synchronous) contralateral breast cancer within 3 months after first breast cancer diagnosis

\section{Patients included in} analyses

$N=83,144$

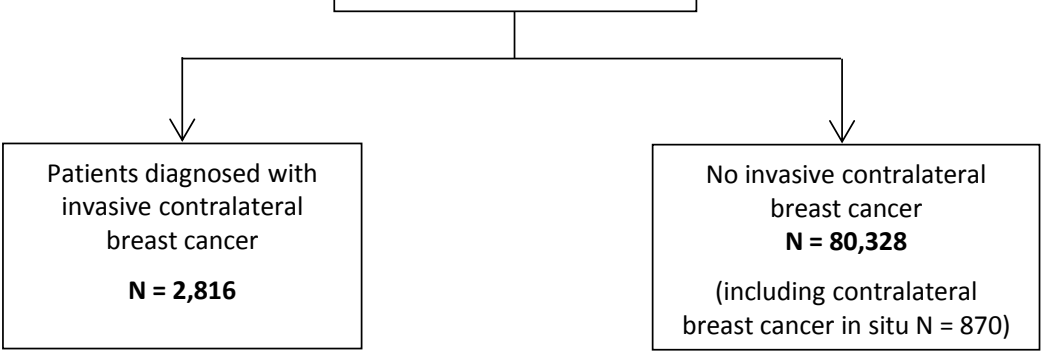


Figure 2

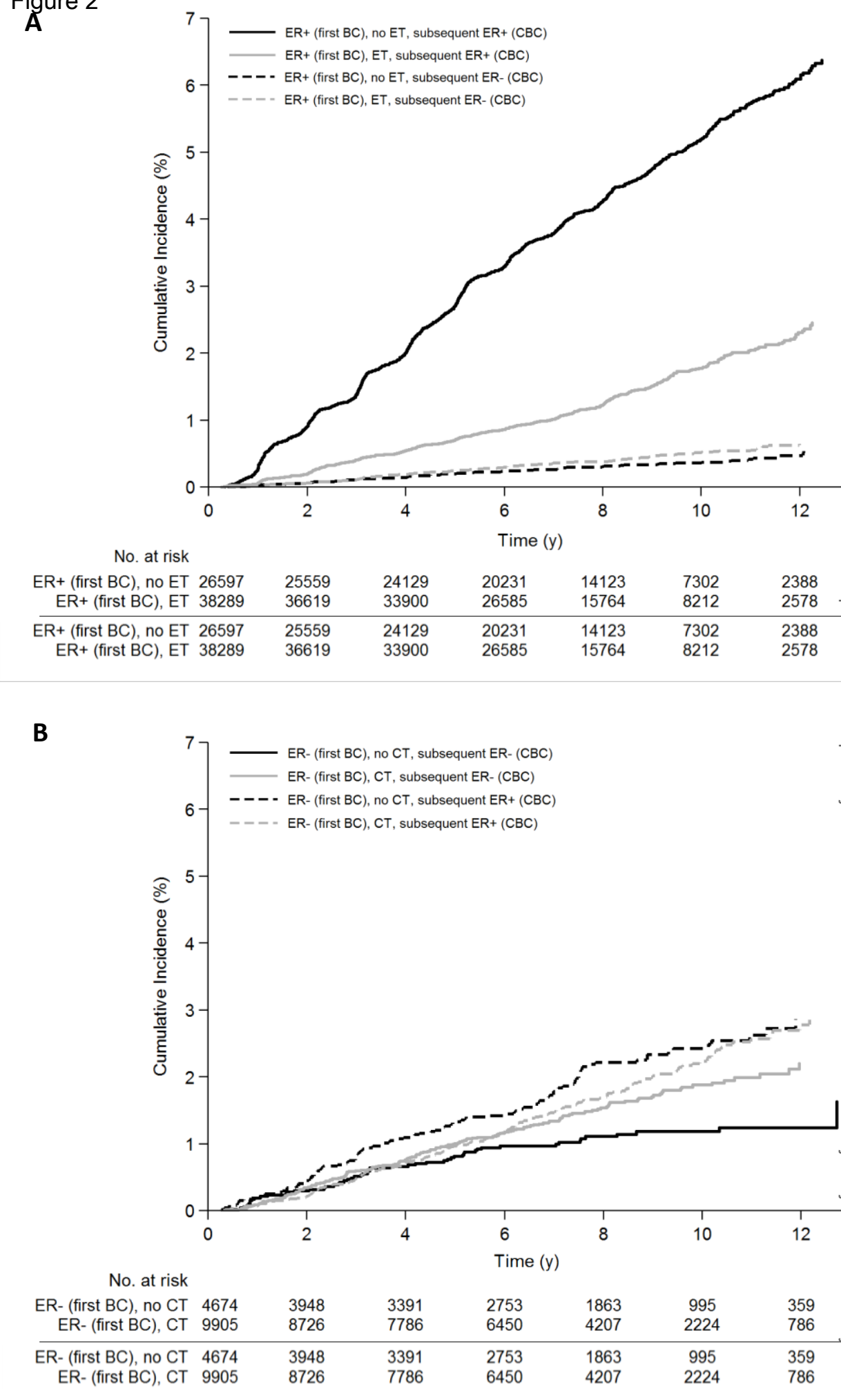

C

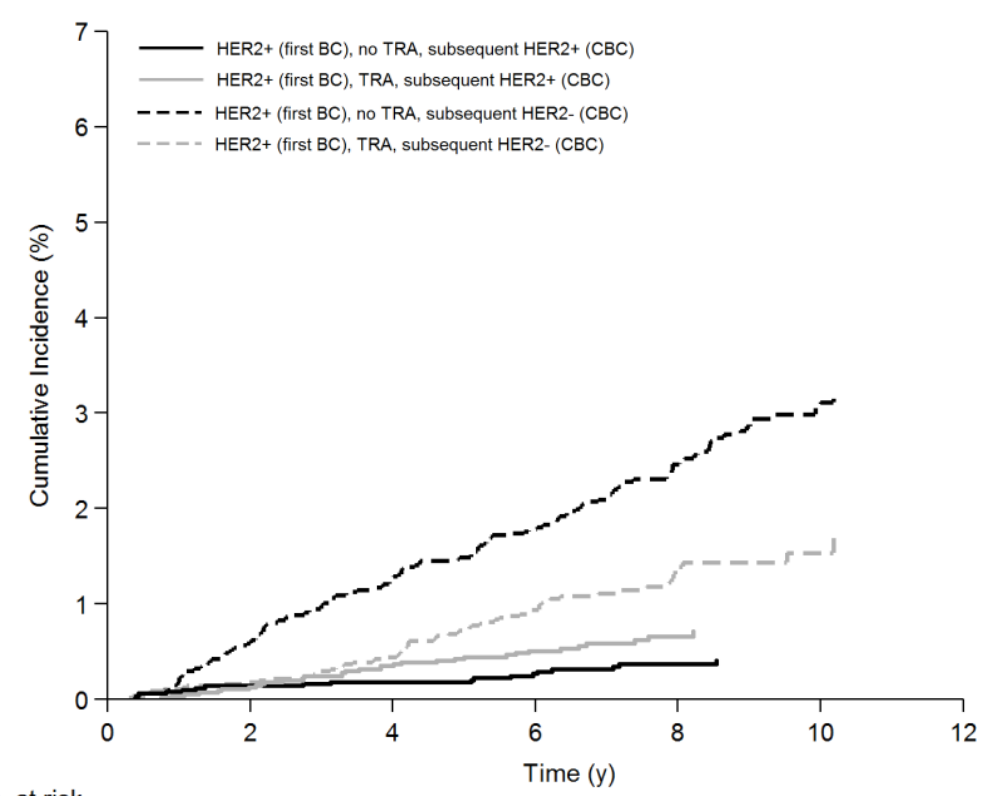

No. at risk

HER2+ (first BC), no TRA 4965

HER2+ (first BC), TRA 5423

$4545 \quad 4106$

HER2+ (first BC), no TRA 4965

HER2+ (first BC), TRA 5423

$\begin{array}{lll}932 & 575 & 0\end{array}$

$\begin{array}{llllll}4545 & 4106 & 3363 & 2218 & 1058 & 0 \\ 5211 & 4881 & 3776 & 1932 & 575 & 0\end{array}$

